\title{
The Influence of a Single Bout of High-Intensity Interval Exercise on Postprandial Lipemia and Glycemia
}

\section{STEPHEN DECKER}

Health and Human Performance Laboratory; Department of Kinesiology and Health Science; Stephen F. Austin State University; Nacogdoches, TX

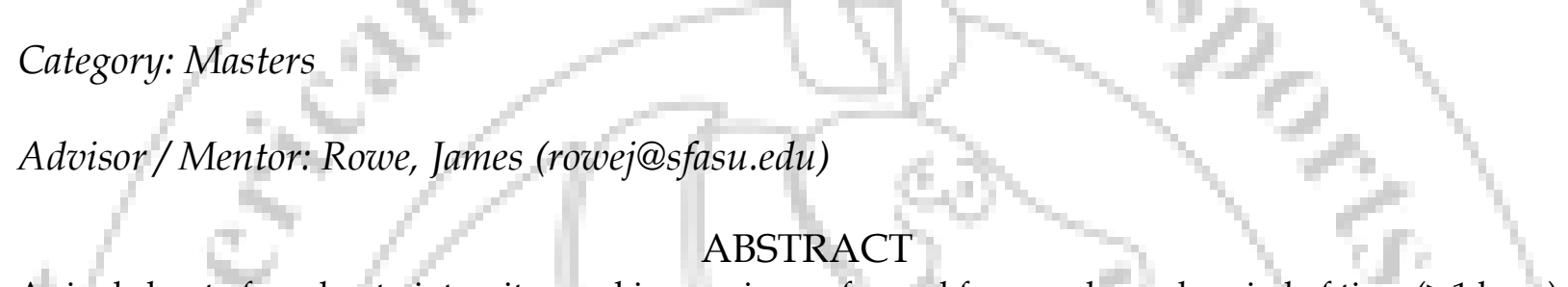

A single bout of moderate-intensity aerobic exercise performed for a prolonged period of time ( $\geq 1$ hour) has been reported to reduce the magnitude of postprandial lipemia and glycemia in both healthy and atrisk populations. High-intensity interval exercise (HIIE) bouts are generally performed in brief intervals $(\leq$ 1 minute) followed with brief periods of rest $(1-3$ minutes) for up to 30 minutes in duration. The influence that a single bout of HIIE would have on postprandial lipemia and glycemia is not clear. PURPOSE: Examine the effects of high-intensity interval exercise (HIIE) on postprandial (PP) triglyceride (TG), glucose, and insulin concentrations following a mixed meal (MM). METHODS: Physically active men $(\mathrm{n}=10$; age $=22.2 \pm 2.1 \mathrm{yrs}$; body mass $=82.7 \pm 13.2 \mathrm{~kg}$; body fat $\%=13.3 \pm 3.1)$ completed two trials in random order: 1) Rest and 2) A single bout of high-intensity interval exercise (HIIE). Both trials were performed at 0800 hours. HIIE consisted of performing eight (15-second) maximal effort sprints on a stationary bicycle. The participants performed the sprints against a resistance equivalent to $7.5 \%$ of the participant's body weight. Each sprint was followed with approximately 3 minutes of passive cycling with no resistance. Rest consisted of sitting quietly for 30 minutes. Approximately 30 minutes following the completion of each trial, a fasting (12hr) blood sample was collected followed by the consumption of the MM providing $7.5 \pm 1.2 \mathrm{kcal} / \mathrm{kgBM}$ (body mass) with a macronutrient composition of $35 \%$ carbohydrate $(\mathrm{CHO}), 5 \%$ protein, and $60 \%$ fat. The MM was blended with whole milk, ice cream, and whipping cream. Blood was collected again at $0.5,1,2$, and 3 hours post-MM and analyzed for TG, insulin, and glucose concentration. Postprandial responses were quantified via the incremental area under the curve $\left(A U C_{I}\right)$ using the trapezoidal method. Significant differences $(p<.05)$ between trials were determined using a one-way, repeated measures ANOVA and Bonferroni post hoc test. RESULTS: The duration of the HIIE was 24 minutes (not including a 5-minute warm up). HIIE expended 90.1 $\pm 11.8 \mathrm{kcal}$. HIIE significantly reduced the glucose $\mathrm{AUC}_{\mathrm{I}}$ (Rest: $\left.9.9 \pm 43.1 \mathrm{mg} \cdot \mathrm{dl}^{-1} \cdot 3 \mathrm{hr}^{-1} ; \mathrm{HIIE}:-39.9 \pm 37.0 \mathrm{mg} \cdot \mathrm{dl}^{-1} \cdot 3 \mathrm{hr}^{-1} ; \mathrm{p}=.010\right)$ and insulin $\mathrm{AUC}_{\mathrm{I}}$ (Rest: $36.2 \pm 25.4 \mu \mathrm{IU} \cdot \mathrm{ml}^{-1} \cdot 3 \mathrm{hr}^{-1}$; HIIE: $\left.5.9 \pm 30.7 \mu \mathrm{IU} \cdot \mathrm{ml}^{-1} \cdot 3 \mathrm{hr}^{-1} ; \mathrm{p}=.035\right)$ with no significant effect on TG AUC (Rest:

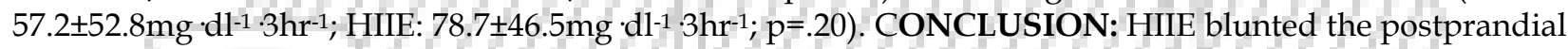
glucose and insulin response to a high-fat mixed meal in young physically active men. The lack of change in the postprandial triglyceride concentration might be explained by the low energy expenditure of the HIIE due to its short duration. Future investigations should evaluate the applicability of HIIE within an atrisk population (i.e. obesity, diabetes). This study was supported by the Stephen F. Austin State University Research Pilot Study Grant and the Texas ACSM Student Research Development Grant. 